Aletheia

ISSN: 1853-3701

publicaciones@fahce.unlp.edu.ar

Universidad Nacional de La Plata

Argentina

\title{
Potencia Tortillera: memorias del activismo lésbico en primera persona. Aprendizajes y desafíos del archivo digitalizado del activismo lésbico en Argentina
}

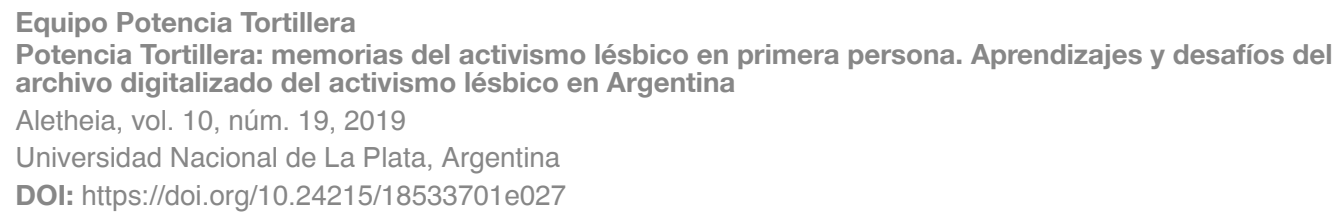

Potencia Tortillera: memorias del activismo lésbico en primera persona. Aprendizajes y desafíos del archivo digitalizado del activismo lésbico en Argentina

Aletheia, vol. 10, núm. 19, 2019

Universidad Nacional de La Plata, Argentina

DOI: https://doi.org/10.24215/18533701e027

Esta obra está bajo una Licencia Creative Commons Atribución-NoComercial-Compartirlgual 4.0 Internacional. 
Dossier: Memorias desde las disidencias sexo-genéricas. Preguntas incómodas para desmontar el cisexismo heterosexual.

\section{Potencia Tortillera: memorias del activismo lésbico en primera persona. Aprendizajes y desafíos del archivo digitalizado del activismo lésbico en Argentina}

Potencia tortillera: memories of lesbian activism in first person. Learnings and challenges of the digitalized archive of lesbian activism in Argentina

Equipo Potencia Tortillera

DOI: https://doi.org/10.24215/18533701e027

Archivo Digitalizado del Activismo Lésbico en Argentina

Potencia Tortillera, Argentina

memorialesbica2@gmail.com

Recepción: 02 Noviembre 2019

Aprobación: 29 Noviembre 2019

Recepción: 02 Noviembre 2019

Aprobación: 29 Noviembre 2019

\section{Resumen:}

En este trabajo nos interesa compartir nuestra experiencia en la realización de Potencia Tortillera -archivo digitalizado del activismo lésbico en Argentina- en el que desde el año 2011 y de modo autogestivo, autónomo y horizontal, nos proponemos recuperar las memorias y apropiarnos de nuestra historia colectiva con el objetivo de romper los silenciamientos que la heterosexualidad obligatoria impone a nuestras vidas y de evitar nuevos borramientos.

Palabras clave: Activismo lésbico, Memorias disidentes, Archivo digitalizado.

\section{ABstract:}

This is our experience of the production of Potencia Tortillera -archivo digitalizado del activismo lésbico en Argentina [digital archive of lesbian activism]- through which we propose to recover memories and appropriate our collective history. This production is self-managed, autonomous and horizontal. Our aim is to disrupt the silencing imposed on our lives by compulsory heterosexuality, and to avoid further erasures.

KeYWORDS: Lesbian activism, Dissident memories, Digital archive.

“Quizás la memoria es un lugar donde residen algunas de las emociones más conflictivas. Puede ser devastador y creativo. No podemos recordar todas las cosas, porque eso paralizaría la mente. Hasta cierto punto, el olvido nos permite afirmar la vida, y eso es lo más importante para aquellos que han sufrido un trauma. Pero en Argentina y Chile, y en otros lugares donde las poblaciones han sido asesinadas por el Estado anterior y la gente sigue desapareciendo, es crucial que los archivos, como los que se encuentran en los museos de la memoria, se financien, se conozcan y circulen. La memoria del pasado también puede vincularse con una imaginación del futuro...

Debemos reconocer de inmediato la singularidad de nuestras vidas, pero también ver las formas en que nuestras vidas se cruzan con otras. Si contamos historias o hacemos imágenes de nuestras propias historias, encontramos los lugares donde una vida está vinculada con otra vida. Ese es el espacio de relación, la historia de la ruptura y la posibilidad de un vínculo futuro". (Boutler, 2019)

\section{MEMORIA COMO RESISTENCIA A LA INVISIBILIDAD}

Durante el transcurso del año 2011 las iniciadoras del archivo motorizamos una serie de encuentros, que se dieron en llamar "Diálogos críticos del activismo lésbico", con el fin de poner en debate algunos temas sobre los que nos parecía importante reflexionar colectivamente. Los diálogos fueron un espacio contingente 
gestado como una apuesta por fisurar la clausura del debate político que, interpretamos, se dio por la fuerza hegemónica de la demanda del matrimonio igualitario en la Argentina ${ }^{1}$; construirnos como interlocutoras legítimas entre las propias lesbianas, con nuestras perspectivas, voces, cuerpos y estéticas heterogéneas y hasta antagónicas; circular saberes y memorias que de otro modo quedan minimizados o excluidos de lo público; poner a vagar la imaginación política más allá de lo delimitado por la razón instrumental de las agendas del consenso y demandas al Estado. De las conversaciones internas que sostuvimos para la concreción de los Diálogos surgió también la idea de generar el archivo. Por lo tanto, durante ese año 2011, estuvimos trabajando en paralelo en la concreción de los Diálogos y la construcción del blog-archivo, que se hizo público en septiembre de dicho año.

Somos un puñado de activistas lesbianas a quienes nos juntó el deseo de recuperar nuestra memoria y apropiarnos de nuestra historia colectiva, con el objetivo de romper los silenciamientos que la heterosexualidad obligatoria impone a nuestras vidas y de evitar nuevos borramientos. Nos impulsaron algunas preocupaciones: que la historia del activismo lésbico en Argentina no se registra o cuando se hace no aparece en la forma que consideramos adecuada; el deterioro de los materiales de nuestras colecciones propias; $y$, por último, que se estaba perdiendo la transmisión 'intergeneracional' entre activistas más antiguas y otras más nuevas.

Entendemos que estas pérdidas tienen como efecto un empobrecimiento de la memoria colectiva, el extravío de recursos propios, la invisibilidad de la creatividad, la sensación agobiante de estar siempre partiendo de cero, y la imposibilidad para las nuevas generaciones de activistas de inscribirse en una historia política configurada por un acervo de experiencias y pensamientos a los cuales recurrir, para tomarlos, dejarlos, complejizarlos, pero que estuvieron ahí, ensayados ya por otras lesbianas. La idea fue recuperar esa constelación de prácticas, discursos, estéticas y afectos que componen ese movimiento zigzagueante, emergente y subterráneo a la vez, del activismo lésbico, con sus afinidades, disputas y antagonismos que expresan la inestabilidad y mutación de todo formato identitario.

Así surgió el blog "Archivo Digitalizado del Activismo Lésbico Potencia Tortillera"2, que intenta oficiar de archivo de las producciones del activismo lésbico en nuestro país. En la actualidad contiene más de mil posteos que van desde el año 1970 hasta el presente. El nombre del blog no describe una experiencia particular del activismo, sino que pone de relieve esa multiplicidad de acciones, textos, cuerpos que, en un tejido muchas veces fragmentado y otras veces con tramas más tupidas, vamos haciendo movimiento, visibilizando las identidades lésbicas y luchando contra el régimen político de la heterosexualidad.

\section{ArChIVo COMO BIEN COMÚN}

Hicimos el archivo prácticamente sin antecedentes de los cuales tomar ideas o experiencias, porque no existía en Argentina ningún archivo lésbico, ni LGBTIQ, ni feminista, sólo colecciones particulares como las nuestras propias y las de otras compañeras que colaboran con nosotras aportando materiales. El único que conocíamos, que fue fuente de mucha inspiración y aprendizaje es el Lesbian Herstory Archives ${ }^{3}$, de Nueva York, fundado por la activista lesbiana Joan Nestle en 1974, archivo que durante años funcionó en su propio departamento. El Lesbian Herstory Archives es una organización de base, sostenida por activistas y voluntarias. Aunque posee características que lo hicieron particular y único (como la disposición casi hogareña de los lugares de consulta, que lo hace muy acogedor), es un archivo en el sentido más convencional del término, o sea está ubicado en un edificio, aloja una amplia variedad de materiales, no solo documentos de activistas, sino también infinidad de objetos de la vida cotidiana, que las lesbianas fueron donando a través de los años. Se puede acceder directamente a los objetos, que a su vez están catalogados de manera sistemática y rigurosa. Asimismo, consta con personal especializado en el resguardo y conservación de los materiales. Implementar un archivo de estas características era inviable para nosotras por la gran cantidad de recursos 
humanos y económicos requeridos para mantenerlo, y por lo restrictivo que resulta para quienes se interesan en consultarlo, ya que el acceso a la información necesariamente supone trasladarse a un lugar específico, en horarios determinados. Si bien nuestro archivo tiene la desventaja de no poder acceder físicamente a los materiales y la imposibilidad de realizar una sistematización rigurosa, tiene la virtud de resolver las dificultades antes mencionadas y, por otro lado, al realizar el trabajo de digitalización solucionamos (con un costo mínimo), el problema del deterioro de los materiales, que siguen alojados en nuestros domicilios particulares. Por otra parte, el crecimiento de las TIC y las redes sociales exige la utilización de herramientas más dinámicas y acordes a las nuevas modalidades comunicacionales. El formato de blog-archivo habilita la incorporación de muchísima información cuya fuente son las redes sociales, y permite el acceso público libre y gratuito a la información. En este sentido, el archivo puede ser pensado desde la óptica de los bienes comunes (Federici, 2004, 2010). Además, optar por esta modalidad nos permitió plantear un estilo de trabajo descentralizado, conformando un equipo multigeográfico que actualmente está integrado por lesbianas de Chubut, Neuquén, CABA, y Santa Fe.

No se trata de pensar al archivo como un logro de unidad. Entendemos que el concepto de "unidad" está sobrevalorado en ciertos ámbitos del movimiento LGBTIQ: aparece como un anhelo, se escucha repetidamente la demanda de "por qué no se unen todas las organizaciones, si todxs queremos lo mismo". En este sentido, la unidad funciona como un concepto de homogeneización y negación de diferencias políticas e ideológicas, de decisiones estratégicas, de privilegios desigualmente repartidos, e incluso de historias personales de amistad, enemistad, amor y rupturas que muchas veces también marcan el ritmo de alianzas y organizaciones. Entonces nuestra intención es confrontar la negación de las diferencias, la imposición de un curso histórico presentado como único, y mostrar lo que hacemos todas para mostrar que tal unidad no existe. Mostramos lo que hacen nuestras amigas, y también lo que hacen aquellas con las que nada compartimos o con las que estamos enemistadas, no porque creamos en la objetividad, sino porque nos interesan la multiplicidad, la divergencia e incluso la dispersión.

Nuestra decisión de incluir, en la medida en que llegue a nuestro conocimiento, todo lo hecho por todas las activistas lesbianas, es una decisión que pretende socializar documentación y saberes, habilitando a que cada lectorx tome de él lo que necesite, haga su propia historia, construya su propio relato del movimiento, reconstruya las afinidades y desavenencias que le interese encontrar.

Es decir, el archivo puede ser pensado desde el concepto de los bienes comunes (Federici, 2004, 2010), pero no como un espacio de unidad, sino como territorio o bien cultural que está a disposición para una comunidad, y que cada quien utiliza como necesita. Entendemos que lo más interesante del planteo de esta economista marxista feminista es que piensa a los bienes comunes como aquello que es sujeto a cercamientos que lo privatizan en cada ronda de acumulación de capital. Y si bien ella se refiere al capital material, está visto que podemos extrapolarlo al capital cultural y simbólico. La tarea es resistir el cercamiento, la apropiación de los bienes comunes por particulares que excluyen al resto. Y con "particulares" no nos referimos exclusivamente a personas individuales, sino explícitamente al Estado y a los gobiernos.

\section{AutOgestión Y HORIZONTALIDAD COMO PRINCIPIOS DE ORGANIZACIÓN}

Desde sus orígenes el archivo se propuso como autogestivo/autónomo, y por ende autofinanciado. Entendemos autogestión desde el punto de vista libertario, donde apoyo mutuo, autogobierno, organización federativa en torno al trabajo, propiedad colectiva, autoorganización, son la metodología de este concepto. A esto le sumamos la horizontalidad, principio feminista histórico que, lamentablemente, no siempre se cumple en las organizaciones feministas actuales. A partir de la autogestión intentamos ser generadoras de articulación a partir del encuentro, la reflexión y la coordinación entre pares para llevar adelante la propuesta, intentando dejar atrás la idea que un grupo y/o institución necesita tener unx directorx o unx líder/esa 
para poder funcionar. Buscamos subvertir con nuestras prácticas las lógicas clásicas de funcionamiento del capitalismo, la heterosexualidad obligatoria y el patriarcado.

Estamos convencidas de que somos las propias lesbianas quienes debemos dar cuenta de nuestra existencia, y de que no se necesitan demasiados conocimientos previos para encarar la labor del archivo; en el devenir del trabajo fuimos aprendiendo, y transmitiendo los conocimientos adquiridos a las nuevas integrantes del equipo.

\section{Dificultades y DESAFÍos}

El archivo está en permanente construcción. Hacemos posteos de los acontecimientos actuales y estamos constantemente incorporando nuevos materiales que vamos encontrando en el proceso de recuperación histórica, producto de nuestro trabajo de investigación o aportados por otrxs activistas.

Podemos decir que tenemos una suerte de "agenda" o de temas clave que nos interesa rescatar cada año, que pueden verse reflejados en las etiquetas, y que están también en construcción, porque las fechas van renovando sus sentidos para el movimiento y el activismo, y vamos redefiniendo cómo dar cuenta de las transformaciones, en la medida de lo posible. Por ejemplo, respecto de fechas clave como el 7 de marzo, el blog-archivo funciona también como registro de esas transformaciones, desde el asesinato de la Pepa Gaitán hasta hoy, que es conocido como el Día de la Visibilidad Lésbica.

Si bien la construcción del archivo comenzó con la digitalización de los archivos personales de algunas de nosotras, la intención es siempre lograr la apropiación del mismo por parte del colectivo lésbico, no sólo como usuarias del contenido, sino procurando que envíen materiales o nos informen sobre las actividades que realizan. Las "estrategias" que hemos implementado hasta el momento no han tenido el resultado que esperábamos, y ésta sigue siendo una de nuestras mayores preocupaciones, que nos convoca a seguir pensando y ensayando formas posibles para lograr que sean más las organizaciones y/o personas que nos envíen los registros de sus intervenciones y producciones, y que el blog-archivo registre del modo más rico posible el incremento y las complejidades de los activismos actuales y del pasado reciente.

En relación con el trabajo de recuperación histórica, uno de los mayores desafíos sigue siendo encontrar información sobre los activismos lésbicos durante la época de la última dictadura militar en Argentina, y anteriores a esa fecha. La mayor dificultad radica en el hecho de que muchxs de lxs activistas de esa época, viéndose forzadxs a la clandestinidad por razones ideológicas o por la represión policial, utilizaban seudónimos, con lo cual es una tarea ardua encontrar esas fuentes ${ }^{4}$.

La conformación de un equipo de trabajo multigeográfico e intergeneracional autónomo y autogestivo, es otro de los desafíos que, a fuerza de ensayo, error y revisiones constantes, ha generado múltiples aprendizajes. Respecto de nuestro trabajo, la apropiación de las Nuevas Tecnologías de la Información y la Comunicación ha sido un reto.

Mencionamos anteriormente, en el apartado sobre bienes comunes, la imposibilidad que presenta el modelo de blog-archivo de realizar un sistema de catalogación y sistematización riguroso. En este sentido nos hemos visto en la necesidad de crear un método de sistematización propio con las escasas herramientas que nos permite la aplicación. Esas herramientas son: la datación por fecha y las etiquetas. La posibilidad de fechar cada posteo, incluso con fechas de décadas anteriores a la creación del blog, habilita una primera y fundamental organización de la información, la datación, que permite a lxs usuarios encontrar rápidamente los materiales por año y por mes. Por otra parte, descubrimos que el uso de las etiquetas era la forma de dar cuenta de la clasificación temática y geográfica de los materiales. La clasificación geográfica por este método nos permite dar cuenta de la provincia donde se origina la actividad registrada, en tanto que la localidad específica se indica en cada posteo en particular. En relación con las temáticas y/o tipos de acciones que registramos, consideramos tres categorías principales: "Política", "Producción Teórica" y "Producción Artística". A su vez, dentro de estas categorías, elaboramos una serie de subcategorías, que están 
en permanente construcción. A modo de ejemplo, en la categoría "Producción Teórica" podemos encontrar, como subcategorías temáticas: lesbofobia, pedagogía, violencia entre lesbianas, teoría queer, entre otras. La disposición de las etiquetas en el blog permite el acceso fácil y rápido a esta clasificación.

Finalmente, también se pueden encontrar textos y artículos que hablan sobre el propio archivo, sobre el blog Potencia Tortillera, con diferentes enfoques y apuestas, de autorxs individuales o de producción colectiva entre las que se cuentan notas periodísticas sobre el blog-archivo y presentaciones de las propias responsables de Potencia Tortillera (de las cuales surgen las ideas acá presentadas). Estos textos, académicos y/o poéticos, hacen parte de esos materiales que recopilamos y ponemos a disposición.

Siempre tuvimos una concepción amplia del concepto de activismo y, en este sentido en los últimos 2 años hemos creído conveniente y necesaria la incorporación de materiales que den cuenta de las múltiples y variadas producciones de lesbianas en distintos lenguajes artísticos ${ }^{5}$ y en el ámbito del posporno. En este mismo sentido estamos encarando un nuevo proyecto en pos de recuperar y visibilizar los modos de existencia, de sociabilidad y la vida cotidiana de las lesbianas en las décadas de los ' 60 , '70 y ' 80 del siglo pasado, en la Argentina.

Desde 2011 a hoy se han dado múltiples transformaciones. Existen actualmente experiencias de archivos en Argentina que rescatan voces, relatos y materiales de colectivxs que habían sido invisibilizados y/o silenciados, como el archivo de la memoria trans. En este proceso, las nociones respecto de lo que significa un "archivo" también se fueron modificando y están en permanente disputa, desde la pregunta de qué cuenta como archivable hasta quiénes deberían hacer la tarea de registro o en quiénes depositar el resguardo y la accesibilidad a los materiales, como así también, y en sintonía con Cvetkovich (2003/2018), la significación del archivo no solo como un reservorio de memoria y de conocimientos colectivos sino también de sentimientos, el lugar donde tramitamos el duelo de nuestras muertas y celebramos las luchas compartidas, el sitio donde podemos recurrir cada vez que necesitamos resignificar nuestras identidades y nuestras vidas, la de cada una y la de todas.

\section{RefEREnCias}

Butler, J. (2019). "La memoria del pasado también puede vincularse con una imaginación del futuro". Entrevista de Claudia Vásquez Haro. Espacio Memoria y Derechos Humanos (ex ESMA). Buenos Aires, Argentina. Recuperado de http://www.espaciomemoria.ar/2019/04/24/judith-butler-la-memoria-del-pasado-también-p uede-vincularse-con-una-imaginacion-del-futuro/

Cvetkovich, A. (2018). Un Archivo de Sentimientos. Trauma, sexualidad y culturas públicas lesbianas. (Javier Sáez del Álamo, trad.). Barcelona: Bellaterra.

Federici, S. (2010). Calibán y la Bruja. Mujeres, cuerpos y acumulación originaria. (Verónica Hendel y Leopoldo Sebastián Touza, trads.). Madrid: Traficantes de Sueños.

\section{Anexo Registro Fotográfico}

Las fotos que compartimos a continuación son a título ilustrativo, no tienen la pretensión de ser representativas de la amplia diversidad y de la cantidad (que suman varios miles) que se pueden encontrar en el archivo. Cada una de las integrantes del equipo, eligió una que le resultaba significativa por motivos afectivos, políticos o ambos. 

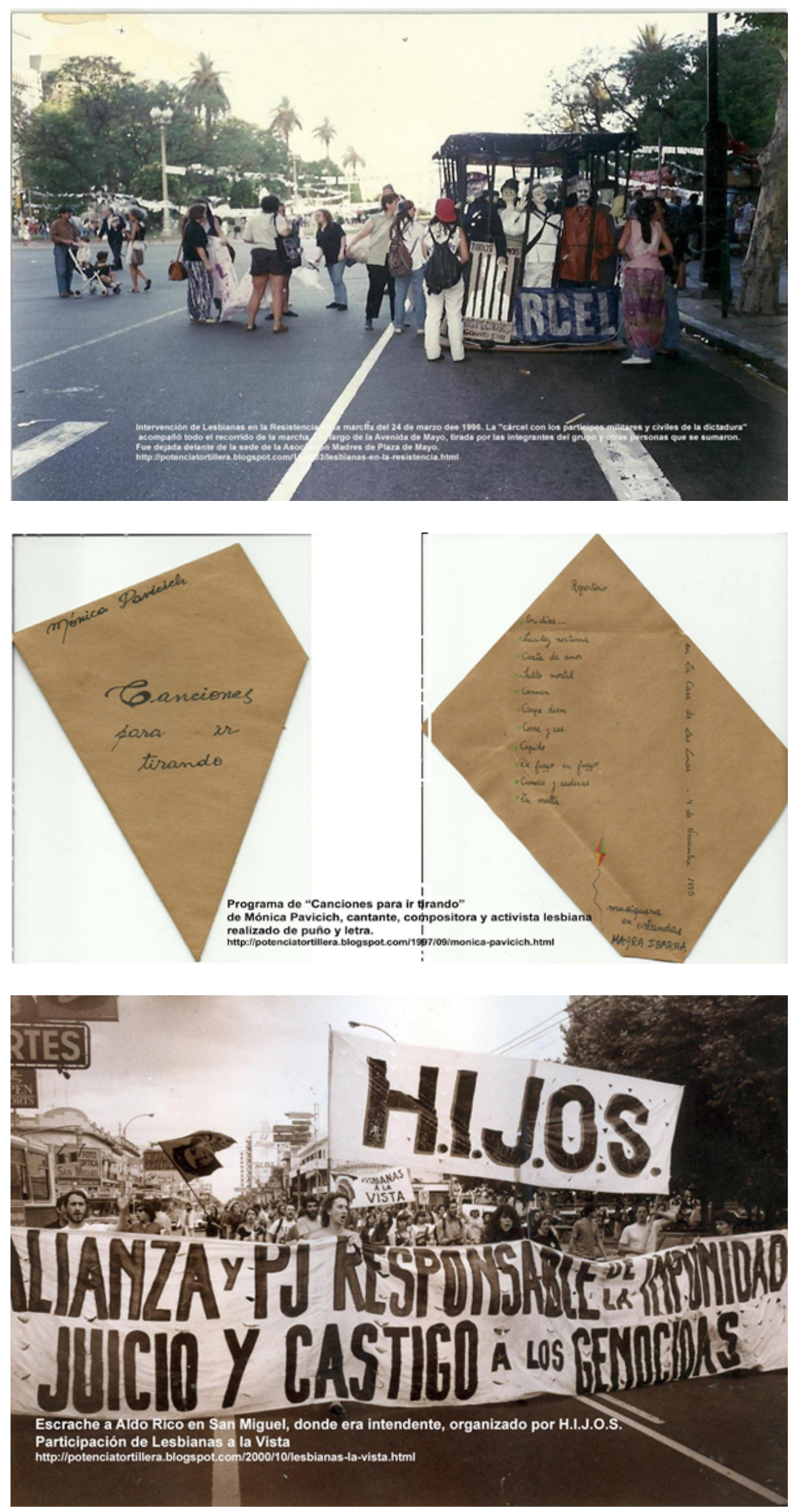


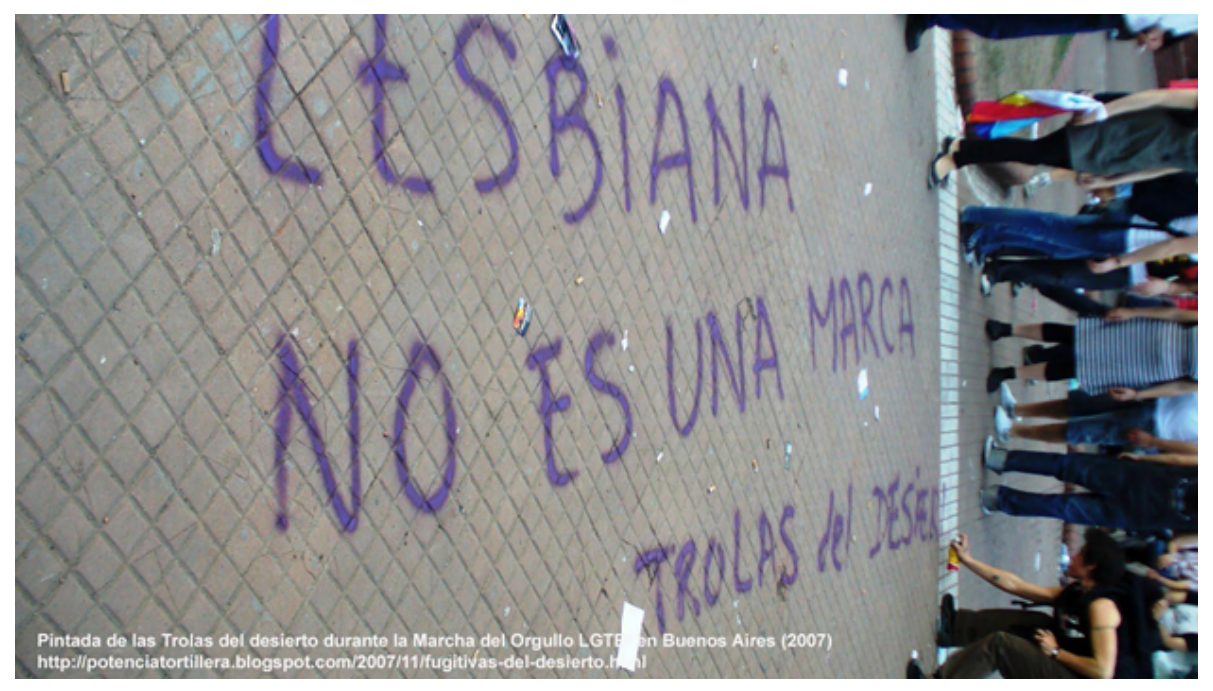

\section{Notas}

1 Ley 26.618 - Matrimonio civil, 2010. A partir de la sanción de esta ley (conocida como "ley de matrimonio igualitario") en julio de 2010, la Argentina se convirtió en el primer país en América Latina en reconocer el matrimonio entre personas del mismo sexo.

2 Se puede visitar el sitio en el siguiente link: http://potenciatortillera.blogspot.com/2017/12/archivo-digitalizado-delactivismo.html

3 Se puede visitar el sitio en el siguiente link: http://www.lesbianherstoryarchives.org/

4 Ver diario crónica sobre unas pintadas del Grupo Safo de 1973, (http://potenciatortillera.blogspot.com/1973/04 /grupo-safo.html); revista Somos (http://potenciatortillera.blogspot.com/1973/12/revista-somos.html); boletín del Movimiento de Liberación Homosexual de Rosario de 1984 (http://potenciatortillera.blogspot.com/1984/01/movim iento-de-liberacion-homosexual-rosario.html).

5 "Ovario Uno", un poema de Marta Ferro que fue publicado en Come Out! del Gay Liberation Front de New York en septiembre-octubre de 1970 (http://potenciatortillera.blogspot.com/1970/10/marta-ferro.html). Celeste Carballo Sandra Mihanovich Mujer contra mujer (http://potenciatortillera.blogspot.com/1989/11/celeste-carballo-sandra-mi hanovich.html).

\section{BY-NC-SA}

